\title{
The ACTH(4-9) Analog Org2766 Modulates the Behavioral Changes Induced by NMDA and the NMDA Receptor Antagonist AP5
}

\author{
Berry M. Spruijt, Marlou Josephy, Inge Van Rijzingen, and Hans Maaswinkel \\ Institute of Molecular Biology and Rudolf Magnus Institute for Medical Pharmacology, University of Utrecht, NL-3584 CH \\ Utrecht, The Netherlands
}

In studies on aged and brain-lesioned rats the chronic administration of the ACTH(4-9) analog Org2766 has been demonstrated to improve the behavioral performance. Those results suggest that maintenance of hippocampal functioning in senescence and facilitation of functional recovery after brain damage are not due to facilitated reinnervation of denervated structures as suggested in previous studies concerning regeneration of the PNS. Alternative explanations may refer to either the neuroprotective properties of the peptide as demonstrated when chronic treatment immediately follows the damage, or a peptide-induced general change in attention that indirectly may contribute to functional recovery. The behavioral effects after acute treatment with ACTH-like peptides have been previously associated with sustained attention by enhanced neuronal excitability of limbic structures. Now, a hypothesis accounting for both neuroprotection and enhanced attention is forwarded by supposing that the peptide exerts its influence by modulation of NMDA receptor activation. Therefore, the acute effects and interactions between the peptide and the NMDA receptor antagonist AP5 (D,L-2-amino-5-phosphonopentanoic acid), and the peptide and NMDA were studied in a water maze and an open field. Impaired water maze performance induced by an acute intracerebroventricular administration of AP5 was counteracted by the ACTH(4-9) analog Org2766, whereas the peptide alone did not affect spatial orientation. NMDA induced extreme locomotor activity at the periphery of the open field. Interestingly, the ACTH(4-9) analog strongly suppressed NMDA-induced enhanced locomotor activity and normalized the pattern of exploratory behavior.

[Key words: ACTH(4-9), NMDA receptor, functional recovery, cognition, rat]

For decades ACTH-like peptides have been known to influence behavior (De Wied and Jolles, 1982). These findings have led in the 1970 s to various clinical trials on cognition in young and aged people using these peptides. An extensive review of the results obtained in those studies strongly suggests that ACTH(49) predominantly enhances nonselective attention and the ability to sustain attention. ACTH(4-9) disinhibits the processing of stimuli irrespective of their relevance (Born et al., 1986).

Received Apr. 29, 1993; revised Sept. 20. 1993; accepted Nov. 17, 1993

Correspondence should be addressed to Dr. B. M. Spruijt, Rudolf Magnus Instituut, Universiteitsweg 100, 3584 CG Utrecht.

Copyright (C) 1994 Society for Neuroscience $0270-6474 / 94 / 143225-06 \$ 05.00 / 0$
Such an effect of the peptide on attention explains the results reported on sociability, mood, and cognition and the variability of effects on cognition, since these experiments heavily depend on the environmental conditions of the task. The presence of distracting cues may impair the performance, whereas sustained attention may facilitate the performance when only few relevant cues are present. Chronic treatment with the ACTH(4-9) analog of aging rats indicated that hippocampal functioning was improved. ACTH(4-9) reduced the morphological correlates of brain aging in the hippocampus (Landfield, 1987) and counteracted age-related behavioral changes on social behavior and spatial orientation (Spruijt, 1992). The effects of the peptide on accelerated normal recovery and the necessity of immediate treatment of the lesioned animals have been described as neurotrophic (neuroprotective) in the PNS (Strand et al., 1989; Gispen, 1990) and CNS (Wolterink et al., 1990). No relation between these neurotrophic effects and the already known "classic" effects on learning and attention has been suggested so far. However, various results in other recovery paradigms, in addition to the neurotrophic (neuroprotective) properties at the time of damage, are reminiscent of the aforementioned effects on attention.

First, deficits in spatial orientation after fimbria fornix (FF) lesion were counteracted by chronic treatment with an $\mathrm{ACTH}(4-$ 9) analog (Pitsikas et al., 1990, 1991; Spruijt et al., 1990) in a relatively short period as compared to the time (6 months) required for reinnervation (Gage et al., 1983a,b). The peptide effects on functional recovery in this paradigm cannot be ascribed to accelerated reinnervation of a denervated brain structure. Second, the timing of peptide administration was not essential for restoration of function after paraventricular (Nyakas et al., 1985) and FF lesions (Van Rijzingen, Josephy, Gispen, and Spruijt, unpublished observations). Third, the rate of contralateral compensation was accelerated by ACTH(4-10) following vestibular deafferentation (Gilchrist et al., 1990).

It is assumed that a peptide-induced state of sustained attention may influence the performance of brain-lesioned animals analogous to what is seen in acutely treated animals. The separately distinguished effects of ACTH-like peptides on neuroprotection (neurotrophic) and sustained attention may have a physiological key element in common: the NMDA receptor. The NMDA receptor is essential for long-term potentiation (Collingridge and Bliss, 1987), a model for changes in the synaptic circuitry underlying memory (McNaughton et al., 1986; Walker and Gold, 1991). Selective impairment in place learning can be induced by the NMDA antagonist AP5 (D,L-2-amino-5phosphonopentanoic acid) as compared to other drugs modulating NMDA receptor activity that has been extensively dem- 
onstrated (McNaughton et al., 1986; Morris et al., 1986; Leung and Desborough, 1988; Jones et al., 1989; Morris, 1989) and elegantly reviewed by McNamara and Skelton (1993).

The present study investigates whether treatment with the ACTH(4-9) analog Org2766 interferes at a behavioral level with modulation of NMDA receptor activation. The effects of the peptide on the NMDA antagonist (AP5) and NMDA itself were studied in the Morris water maze and on locomotor activity in a large open field provided with an object, respectively. Since the first goal of the study is to assess a behavioral interaction, the acute behavioral effects of AP5 and NMDA were used in combination with an acute treatment with the peptide.

\section{Materials and Methods}

\section{Animals}

Male Wistar rats, weighing about $250 \mathrm{gm}$, were housed individually under a reversed day night cycle (lights off at $8 \mathrm{~A} . \mathrm{M}$. and lights on at 8 P.M.) in a humidity- and temperature $\left(21^{\circ} \mathrm{C}\right)$-controlled room. Behavioral tests were performed during the dark period. Three hours prior to the onset of the experiments animals were brought to the experimental room, which was similar to the rooms used for housing.

\section{Surgery and drugs}

Under anesthesia (Hypnorm, $0.1 \mathrm{ml} / 100 \mathrm{gm}$, s.c.) cannulas were placed intracerebroventricularly as described previously (Brakkee et al., 1979) 1 week prior to the onset of the behavioral experiments. AP5 (D,L-2amino-5-phosphonovaleric acid; Sigma) and the AC'1H (4-9) analog Org2766 (Organon B.V., Oss, The Netherlands) were dissolved in $0.9 \%$ saline. ACTH(4-9) was used in concentrations of $10 \mathrm{ng}(N=8), 50 \mathrm{ng}$ $(N=8), 100 \mathrm{ng}(N=6), 1 \mu \mathrm{g}(N=8)$, and $10 \mu \mathrm{g}(N=8)$ for subcutaneous injections. The dose of $1 \mu \mathrm{g}$ given subcutaneously was used for combined treatment with AP5 and NMDA. Preliminary experiments had been carried out to establish an effective dose range for the effects of AP5 in the water maze and demonstrated that animals treated with 10 or 20 $\mu \mathrm{g}$ of AP5 had a very weak muscle tonus and could hardly swim. Therefore, lower doses of AP5 as compared to other studies (Koek et al., 1987; Danysz et al., 1988; Leung et al., 1988; Kim et al., 1991)-3, 4, and $5 \mu \mathrm{g}-$ were used in the present study. NMDA ( $N$-methyl-D-aspartate; Sigma) was dissolved in a Tris buffer with a pH of 7.2. Preliminary experiments were conducted to assess the effective dose for the NMDAinduced increase in locomotor activity without the occurrence of convulsions. A dose of $250 \mathrm{ng}$ of NMDA was chosen as the most effective one.

Rats were injected with AP5 (intracerebroventricularly) and ACTH(49) (subcutaneously) 15 and $60 \mathrm{~min}$ before the test, respectively. Intracerebroventricular injections of ACTH(4-9) or NMDA were given 5 $\min$ before the test. Central and peripheral injections were given in a volume of $3 \mu \mathrm{l}$ (intracerebroventricularly) and $0.5 \mathrm{ml}$ (subcutaneously) per rat, respectively. Control rats received the same amount of the dissolvant.

\section{Behavioral tests}

The effects of AP5 have been assessed in a Morris water maze and the large open field; the effects of NMDA appeared most sensitive to locomotion in a large open field. Thus, these two tasks were chosen as appropriate tools for revealing interactions of the ACTH(4-9) analog Org2766 with the hehavioral consequences of NMDA receptor activation.

Morris water maze. On four consecutive days the animals were given four acquisition trials per day within a period of $15 \mathrm{~min}$ in a swimming pool $(110 \mathrm{~cm}$ diameter, $50 \mathrm{~cm}$ high, filled with water made opaque with chalk powder, temperature $26 \pm 1^{\circ} \mathrm{C}$ ). The basin was divided into four quadrants, each with a starting point, where the rats were put into the water facing the wall. In a random sequence each starting point was used once per day. Rats were given a maximum of $120 \mathrm{sec}$ to find the hidden platform $(8 \mathrm{~cm}$ in diameter, $1 \mathrm{~cm}$ below the surface) in a fixed location in the middle of one of the quadrants. They were allowed to stay on it for $30 \mathrm{sec}$. If they did not find the platform, the experimenter put them onto it for $30 \mathrm{sec}$. Latencies to find the platform and distance swum were automatically registered with a video computer system de- veloped by Spruijt et al. (1992). Both latency times and distances swum to reach the platform have been measured; no differences between latencies and distances have been found. Therefore, only the latencies have been given in the Results. Rats were treated every day before they performed the water maze task.

Large open field. A circular arena (140 cm diameter; sidewall $50 \mathrm{~cm}$ high) madc of dark polycstcr matcrial was used. A metal object of 15 $\times 15 \times 15 \mathrm{~cm}$ was placed in the center of the arena. The same computerized system as described above was used to measure the distance walked and the time spent in the periphery of the arena and in the vicinity of the object $(40 \mathrm{~cm}$ diameter) during a period of $10 \mathrm{~min}$. Pilot studies indicated that possible differences in the pattern of locomotion between different groups are strongly provoked by the presence of an object in the center of the arena.

\section{Experimental design}

Prior to the experiments with AP5, which involved large numbers per group, the effect of ACTH(4-9) alone was extensively studied. Previous studies on recovery have shown that the behavior of nonlesioned animals - repeatedly treated with the peptide alone-was not affected in the paradigms used. In order to investigate whether the acute treatment of the peptide in various doses did affect Morris maze behavior, a doseresponse (doses are mentioned above) study preceded the actual experiment. It was necessary to do the control groups in advance since the number of animals that can be run on one day the Morris maze is limited and we did not want to restrict the number of animals in the other groups. In the first experiment rats were injected intracerebroventricularly with 3,4 , and $5 \mu \mathrm{g}$ AP5 and vehicle (8-10 rats per group) and tested in the water maze. In the second experiment the effect of the ACTH(4-9) analog on the AP5-induced impairment of performance in the water maze was assessed. Rats received $3 \mu \mathrm{g}$ of AP5 only $(N=8)$, or combined with subcutaneous pretreatment of ACTH(4-9) $(N=17)$ or saline $(N=17)$. A similar experiment was done with $5 \mu \mathrm{g}$ of AP5 (seven or eight rats per group). In the third experiment the effects of NMDA and the interaction of AP5 and ACTH(4-9) with NMDA were assessed on locomotor activity in a large open field. Five groups of rats (7-10 animals per group) were treated with vehicle, $3 \mu \mathrm{g}$ of AP5, 250 ng of NMDA, $3 \mu \mathrm{g}$ of AP5 plus $250 \mathrm{ng}$ of NMDA, and $1 \mu \mathrm{g}$ of ACTH(49) plus $250 \mathrm{ng}$ of NMDA. In all experiments, naive groups of rats were used. AP5, ACTH(4-9), and NMDA were injected according to the time schedule described above.

\section{Results}

Acute treatment with the various doses of the ACTH(4-9) analog does not affect the performance in the water maze task (as assessed with an ANOVA on one factor with repeated measurements; Fig. 1). Figure 2 depicts the mean latencies required by the animals treated with different doses of AP5 to find the platform. A regression analysis over all days showed a significant effect for the dose $(T=2.5 ; P<0.016)$. This analysis was followed by a regression analysis per day. On day 2 a significant effect of the dose was reached $(T=2.5 ; P<0.05)$. In Figure 3 the effect of the ACTH(4-9) analog on the impairment induced by $3 \mu \mathrm{g}$ of AP5 is illustrated by the latency times to find the platform over the days for each group. An ANOVA with repeated measurements followed by univariate $F$ tests yielded an overall difference between the groups $[F(2,37)=5.8 ; P<0.01]$. A post hoc Tukey HSD test showed that the differences between the groups are due to significant differences on day 2 and day 4 between the groups treated with AP5 alone and AP5 combined with the ACTH(4-9) analog $(P<0.05)$. Over all days the peptide-treated group did not differ from the control group. The effect of the ACTH(4-9) analog on $5 \mu \mathrm{g}$ AP5 is shown in Figure 4. Again, AP5 impaired the performance, but now the effect of AP5 was not significantly affected by pretreatment with the $\mathrm{ACTH}(4-9)$ analog $[F(2,13)=2.8 ; P<0.1]$, although the curve representing the latency times of animals treated with the ACTH(4-9) analog paralleled those of the AP5-treated animals at a lower level. 


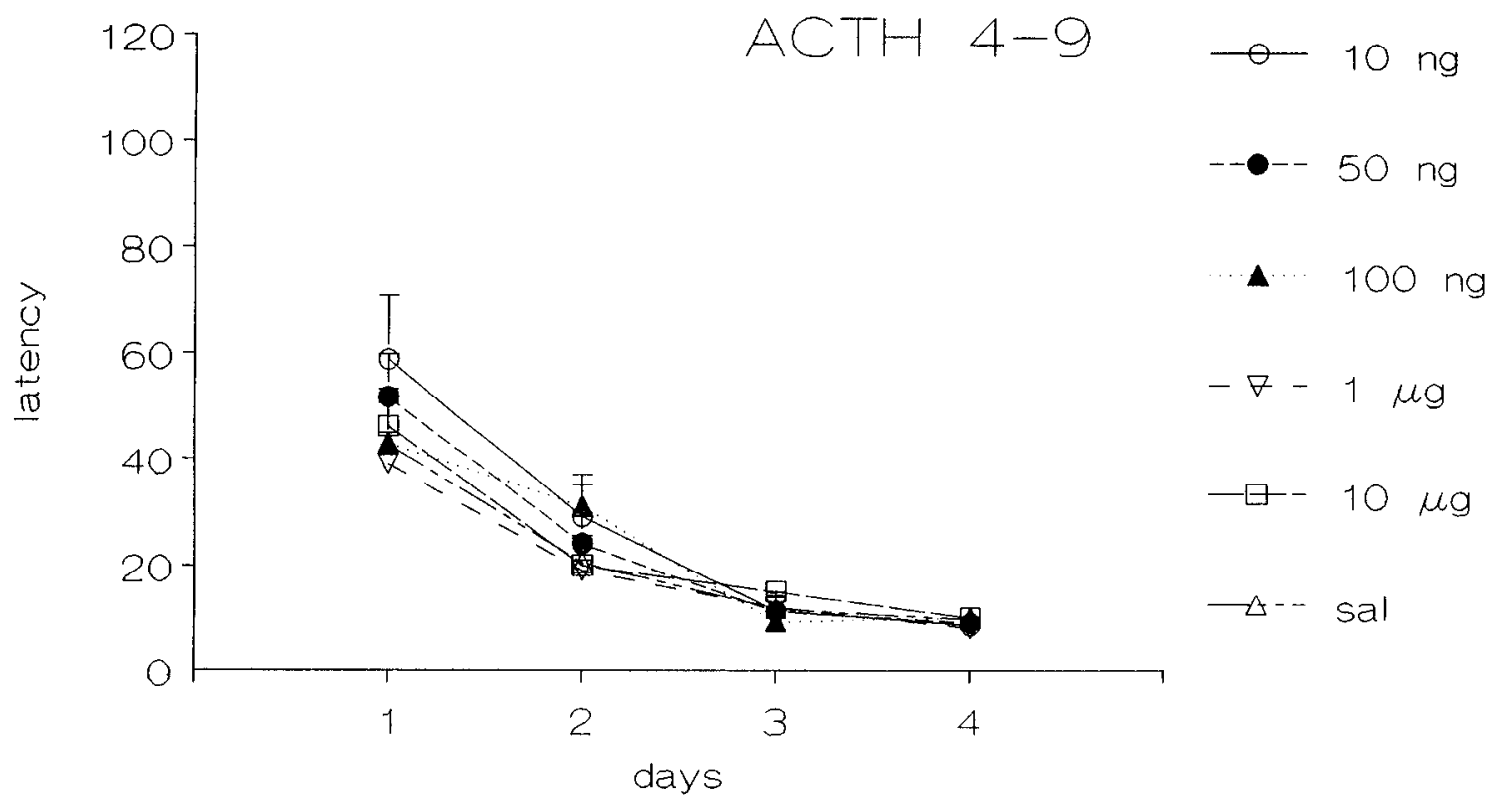

Figure 1. Various doses of ACTH(4-9) did not influence the performance in the Morris water maze. This figure presents the mean latency times (and SEM) of several groups of rats-injected with $10 \mathrm{ng}, 50 \mathrm{ng}, 100 \mathrm{ng}, 1 \mu \mathrm{g}$, and $10 \mu \mathrm{g}$ of the ACTH(4-9) analog and saline $60 \mathrm{~min}$ before the four acquisition trials every day.

In Figure 5 the distance run or walked in the exploration arena is given for the various groups at the periphery of the arena and in the center where the object was located. The main differences are to be seen for locomotor activity at the periphery $[F(4,41)=16.8 ; P<0.0001]$. A post hoc Tukey test demonstratcd that the NMDA-trcatcd animals ran significantly longer distances than all other groups $(P<0.001)$. Rats treated with NMDA and AP5 or ACTH(4-9) did not differ from each other, but both differed from the control group $(P<0.05)$. NMDAtreated animals ran more than twice the distance as compared to the controls. Both the antagonist AP5 and the ACTH(4-9) analog counteracted this dramatic increase in running behavior
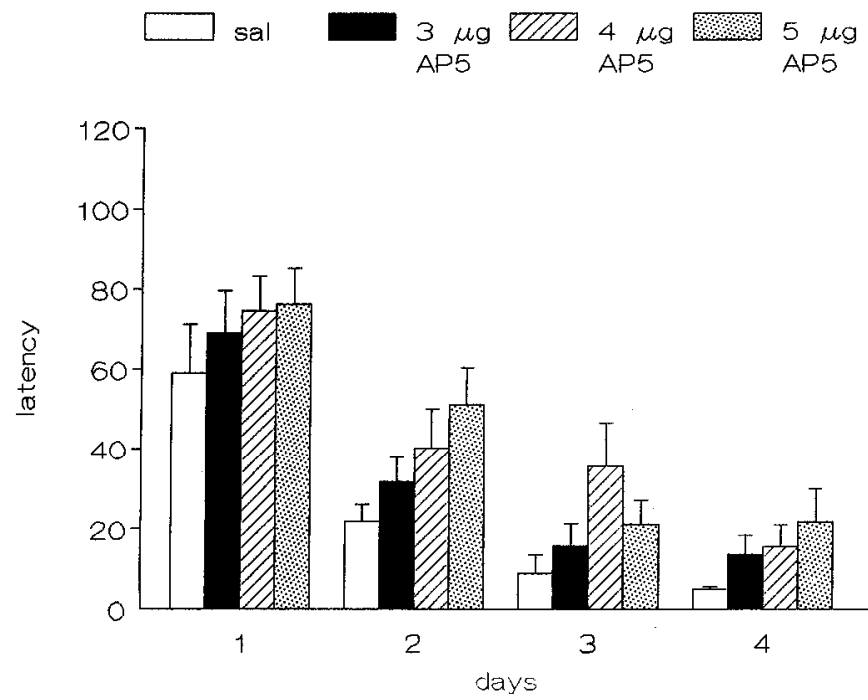

Figure 2. Different doses of the NMDA antagonist AP5 impaired the performance in the Morris water maze. Mean latency times (and SEM) per block of four trials are given for rats injected with saline, $3 \mu \mathrm{g}$ of AP5, $4 \mu \mathrm{g}$ of AP5, and $5 \mu \mathrm{g}$ of AP5 every day $15 \mathrm{~min}$ before the four acquisition trials. for more than $50 \%$. In the middle of the arena an significant overall effect was seen $[F(4,41)=17.0 ; P<0.0001]$, which was primarily due to the increase for the AP5-treated group as shown by a Tukey test, showing that this group walked more in the center than all other groups.

\section{Discussion}

The acquisition of spatial orientation is impaired by a relatively low dose of AP5 $(3 \mu \mathrm{g})$, which is in agreement with findings of others (McNaughton et al., 1986; Morris et al., 1986; Danysz et al., 1988; Kim et al., 1991), who suggested that pretreatment with NMDA or antagonists affects the acquisition of a task. Our

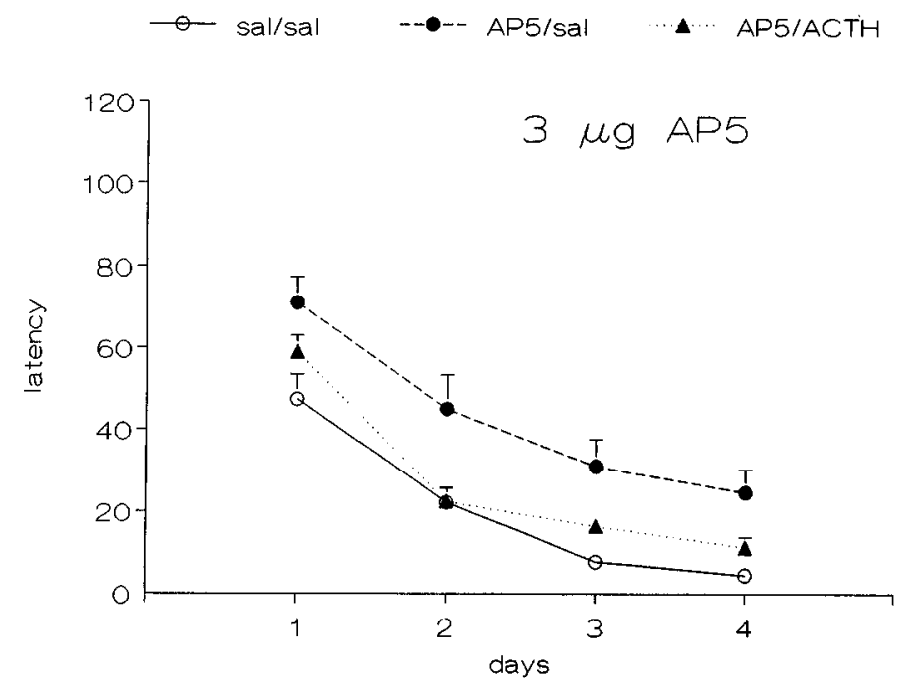

Figure 3. The ACTH(4-9) analog counteracts the AP5-induced impairment in performance in the Morris water maze. Mean latency times per block of four trials (and SEM) for each day are depicted for rats intracerebroventricularly injected with saline, $3 \mu \mathrm{g}$ of AP5, and $3 \mu \mathrm{g}$ of AP5 and ACTH(4-9) 60 min (subcutaneously) before the test and a group treated with saline. 

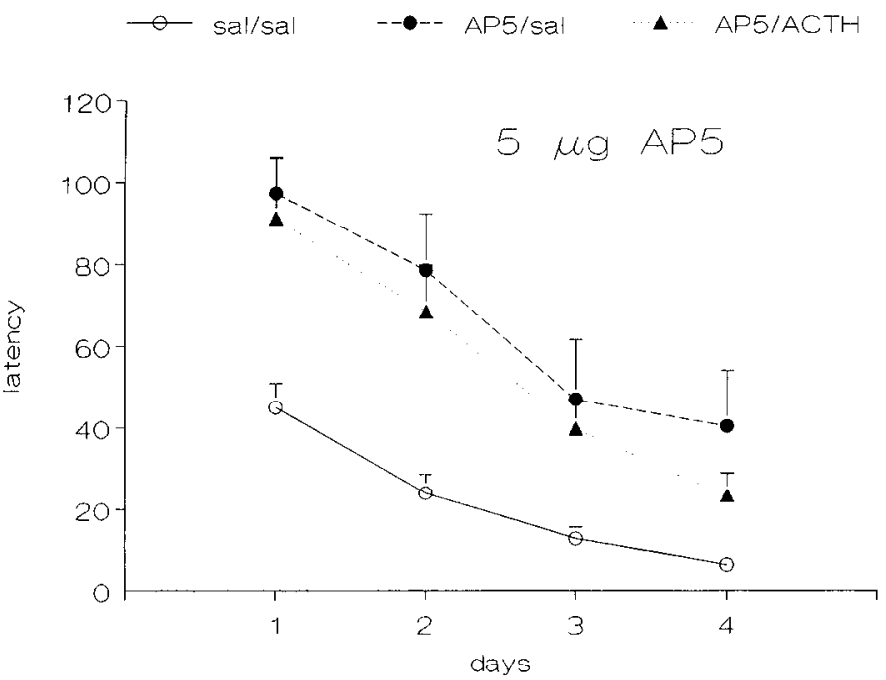

Figure 4. The ACTH(4-9) analog does not counteract the $5 \mu \mathrm{g}$ of AP5induced impairment in the Morris maze. Rats were treated as described in Figure 3 with the exception that a higher dose of AP5 $(5 \mu \mathrm{g})$ was used.

pilot experiments emphasize the importance of using low doses of AP5, since higher doses resulted in motor disturbances interfering with the swimming ability of the rats. The effect of the lowest dose that affected water maze performance was counteracted by a pretreatment with the ACTH(4-9) analog. Although the higher dose of $5 \mu \mathrm{g}$ of AP5 seemed affected, this difference was not significant. Apparently, only the low dose of AP5 can be counteracted by $1 \mu \mathrm{g}$ of $\mathrm{ACTH}(4-9)$. Interestingly, the profound effect of the agonist NMDA on explosive running behavior was also counteracted by the subcutaneously administered peptide. The magnitude of the peptide effect was similar to the effect of the antagonist AP5, despite the differences in the routc of administration (subcutaneous vs intracerebroventricular), indicating that the ACTH(4-9) analog very potently antagonizes the running behavior induced by NMDA. The peptide given alone in various doses and via different routes of admin- istration did not have any behavioral effect either on spatial orientation or on locomotor activity in the arena (data not shown). This lack of any similarity with the NMDA agonist or antagonist indicates that only changes in NMDA receptor activity are modulated; apparently, peptide efficacy appears only if the experimental conditions result in such changes. The finding that ACTH. like peptides might modulate NMDA receptor activity has two major implications: (1) these effects suggest a linkage between the acute behavioral effects usually associated with attention and the effects seen after chronic treatment that have been observed in lesion and/or aging paradigms; (2) this finding may contribute to the elucidation of the pharmacological mechanisms underlying peptide efficacy, which have not yet been identified, but relations between ACTH-like peptides and opioid systems and between these peptides and excitatory neurotransmission have been suggested in previous studies. Both implications will be discussed separately.

\section{Enhanced recovery by modulation of NMDA receptor activity}

It is assumed that chronic trcatment has similar but longcrlasting effects than acute treatment. For understanding the variety of results in recovery studies it is important to realize that modulatory effects of chronic peptide treatment on NMDA receptor activity may affect functional recovery after brain damage in different ways. First, mechanical and neurotoxic lesions result in depolarization and release/leakage of transmitters such as excitatory amino acids (Choi, 1988); counteracting the subsequent NMDA-receptor activation has neuroprotective effects. Beneficial effects of ACTH fragments administered immediately after the damage as seen in various studies (Isaacson and Poplawski, 1983; Hannigan and Isaacson, 1985; Nyakas et al., 1985; Spruijt et al., 1990; Wolterink et al., 1990; Attella et al., 1992) may be partly the consequence of such neuroprotective effects of NMDA receptor modulation. Second, modulation of NMDA receptor activation by peptide treatment with a delay to the time of the damage, but shortly before the time of testing, may affect the performance. It is assumed then that facilitation of NMDA receptor activation forms part of the underlying mechanism of peptide-enhanced nonselective attention. Such direct

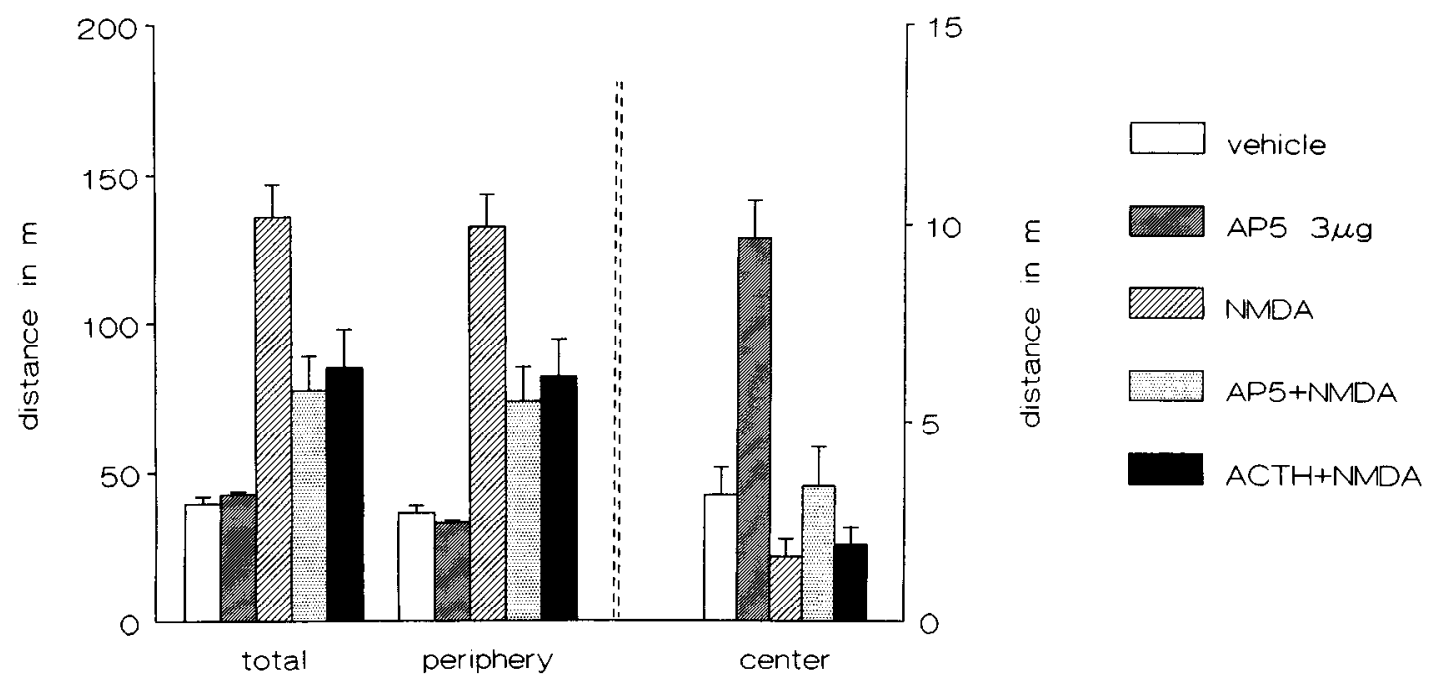

Figure 5. The ACTH(4-9) analog strongly reduces NMDA-induced running behavior. Mean (and SEM) locomotory activity (distance in meters) at the periphery of the arena and in the center near the object is depicted for rats treated (intracerebroventricularly) with saline, 250 ng of NMDA, $250 \mathrm{ng}$ of NMDA and $3 \mu \mathrm{g}$ of AP5, and $250 \mathrm{ng}$ of NMDA and $1 \mu \mathrm{g}$ of ACTH(4-9). 
effects on behavior are independent of the damage and reminiscent of the "classical" behavioral effects in cognition paradigms in animals and human studies; also in recovery studies the nature of the change in behavioral performance depends on the experimental conditions of the tasks and are, therefore, not necessarily recognized as an improvement (Nyakas ct al., 1985; McDaniel et al., 1989; Spruijt et al., 1990). The efficacy of enhanced attention as such in FF-lesioned animals on performance is in agreement with results obtained in experiments showing that additional extra environmental cues compensated for the deficit in performance of the lesioned animals (Maho et al., 1991). Furthermore, results obtained in other studies on recovery (Hannigan and Isaacson, 1985; McDaniel et al., 1989) also suggest an effect of the peptide on attention. Brain damage, especially when it concerns the limbic system, involves disturbances in attention; therefore, peptide efficacy on attention may more easily be detected in lesioned animals as compared to intact animals. Third, a long-lasting enhanced state of attention after chronic peptide treatment (Landfield, 1987; Spruijt, 1992) may indirectly influence synaptic plasticity as is seen in aging studies. The chronic peptide effects (1) on age-related social behavior and spatial orientation (Spruijt, 1992), (2) on a diminished morphological index of brain aging (Landfield, 1987), and (3) on the preserved number of hippocampal mineralocorticoid receptors (Reul et al., 1988) and the inactivation of mineralocorticoid antagonist (RU-28318) by the peptide (Oitzl et al., 1993) are in agreement with a peptide-induced state of sustained attention. There is a clear relation between the behavioral state of an animal and facilitation of synaptic plasticity. Bramham and Srebo (1989) showed that long-term potentiation and long-term depression are strongly modulated by alertness. They presume that general stimulation of CNS activity promotes functional recovery. Also the peptide-facilitated compensation of other brain regions after lesions (Igarashi et al., 1988; Gilchrist et al., 1990) may be induced by a modulatory action of the peptide on the behavioral state and subsequently the synaptic plasticity.

\section{The underlying neural substrate}

There is one study suggesting that the ACTH fragment (4-10) affects directly the NMDA receptor complex (Trifiletti and Pranzatelli, 1991). However, we extensively investigated the effects of our fragment (a 4-9 analog) alone and did not find any effect that could be associated either with a noncompetitive antagonist or with a competitive (ant)agonist. Thus, it seems more likely that peptide effects are the result of an indirect action on NMDA receptor activity. NMDA in low doses induces enhanced locomotor activity; in higher doses (>300 ng) explosive motor running is observed, which is similar to behaviors preceding convulsions induced by GABAergic antagonists (Spruijt et al., 1986). Apart from the effects of the ACTH(4-9) analog on cognition and functional recovery, modulatory effects of ACTHlike neuropeptides on convulsive behaviors have also been noticed (Klein and Livingstone, 1950; Torda and Wolff, 1952; Cottrell et al., 1982; Pentella et al., 1982; Willig and Lagenstein, 1982; Tartara et al., 1983; Goldman and Berman, 1984; Wamil et al., 1991). Especially, Goldman et al. (1987) showed that chronic peptide treatment reduced the development of seizures in amygdala-kindled rats and that acute treatment counteracted the severity of seizures. These authors mentioned a possible effect of the ACTH(4-9) analog on the disruption of normal ionic distribution. The interaction between ACTH fragments and opioids has been studied and evidenced before (Gispen et al., 1975; Terenius et al., 1975; Fekete et al., 1983; Bertolini et al., 1986) but has never been further elucidated. Interestingly, the opioids also have both modulatory effects on neuroprotection, cognition and convulsive/anticonvulsive properties (Tortella, 1988; Bramham, 1992). Therc is abundant cvidence that $\mu$-opioid receptor activation modulates NMDA receptor-mediated responses and thus a peptide interaction with opioids or NMDA receptor activity may have a common cause (Chen and Huang, 1991; Rusin and Randic, 1991; Huang, 1992). The mechanism of action of opioids is complex and involves, among others, $\mathrm{Ca}^{2+}$ currents (Hescheler et al., 1987; Schroeder et al., 1991). Interestingly, the beneficial effect of an ACTH(4-10) analog (BIM 22015) on recovery after spinal cord injury has been demonstrated to depend on $\mathrm{Ca}^{2+}$ levels (Calvet et al., 1992).

The nature of the interaction of $\mathrm{ACTH}(4-9)$ and the behavioral consequences of NMDA receptor activation is far from conclusive and most probably indirect, but the involvement of both ACTH-like peptides and NMDA-like agents in the three common domains-acquisition of behavior, neuronal excitation, and neuronal survival - is intriguing and will enforce further studies on the underlying mechanisms.

\section{References}

Attella MJ, Hoffman WS, Pilotte PM, Stein DG (1992) Effects of MIM-22015, an analog of ACTH(4-10) on functional recovery after frontal cortex injury. Behav Neural Biol 57:1 57-166.

Bertolini A, Poggioli R, Vergoni AV, Castelli M, Guarini S (1986) Evidence that melanocortins are physiological antagonists of opioids. In: Central actions of ACTH and related peptides: symposia of neuroscience (De Wied D, Ferrari W, eds), pp 207-222. Berlin: Springer.

Born I, Fehm L. Voigt KH (1986) ACTH and attention in humans: a review. Neuropsychobiology 15:165-186.

Brakkee JH, Wiegant VM, Gispen WH (1979) A simple technique for rapid implantation of a permanent cannula into the rat brain ventricular system. Lab Anim Sci 929:78-81.

Bramham CR (1992) Opioid receptor dependent long-term potentiation: peptidergic regulation of synaptic plasticity in the hippocampus. Neurochem Int 20:441-455.

Bramham CR, Srebo B (1989) Synaptic plasticity in the hippocampus is modulated by behavioral state. Brain Res 493:74-86.

Calvet M, Drain M, Calvet J (1992) Neuronal firing patterns of organotypic rat spinal cord cultures in normal and in $\mathrm{ACTH} / \alpha-\mathrm{MSH}(4$ 10) analog (BIM 220 15)-supplemented medium. Brain Res 571:218229.

Chen L, Huang LYM (1991) Sustained potentiation of NMDA receptor-mediated glutamate responses through activation of protein $\mathrm{ki}$ nase $C$ by an opioid. Neuron 7:319-326.

Choi DW (1988) Glutamate neurotoxicity and diseases of the nervous system. Neuron 1:623-634.

Collingridge GL, Bliss TVP (1987) NMDA receptors-their role in long-term potentiation. Trends Neurosci 10:288-293.

Cottrell GA, Nyakas AC, Bohus BD, De Wied D (1982) ACTH and MSH reduce the after discharge and behavioral depression following kindling integrative neurohumoral mechanisms physiological and clinical aspects. Budapest: March.

Danysz W, Wrobleski JT, Costa E (1988) Learning impairment in rats by $N$-methyl-D-aspartate receptor antagonists. Neuropharmacology 27:653-656.

De Wied D, Iolles J (1982) Neuropeptides derived from proopiocortin: behavioral, psychological and neurochemical effects. Physiol Rev 62 : 976-1056.

Fekete M, Drago F, Van Ree JM, Bohus B, Wiegant VM, De Wied D (1983) Naltrexone-sensitive behavioral actions of the ACTH(4-9) analog (ORG 2766) Life Sci 32:2193-2204.

Gage FH, Björklund A, Stenevi U, Dunnett SB (1983a) Reinnervation of the partially deafferented hippocampus by compensatory sprouting from spared cholinergic and noradrenergic afferents. Brain Res 268 : 27-37.

Gage FH, Björklund A, Stenevi U, Dunnett SB (1983b) Functional 
correlates of compensatory sprouting by aminergic and cholinergic afferents in the hippocampal formation. Brain Res 268:39-47.

Gilchrist DPD, Smith PF, Darlington CL (1990) ACTH(4-10) accelerates ocular rccovery in guinea pig following vestibular deafferentation. Neurosci Lett 118:14-16.

Gispen WH (1990) Therapeutic potential for melanocortins in peripheral nerve disease. Trends Pharmacol Sci 11:221.

Gispen WH, Buitelaar J, Wiegant VM, Terenius L, De Wied D (1975) Interaction between ACTH fragments, brain opiate receptors and morphine-induced analgesia. Eur J Pharmacol 39:393-399.

Goldman H, Berman RF (1984) Reduction of amygdaloid kindled seizures by an analog of ACTH/MSH. Peptides 5:1061-1065.

Goldman H, Berman RF, Murphy S (1987) ACTH-related peptides, kindling and seizure disorders. In: Hypothalamic dysfunction in neuropsychiatric disorders (Nerozzi D, Goodwin FK, Costa F, eds), pp 317-327. New York: Raven.

Hannigan JH, Isaacson RL (1985) The effects of ORG2766 on the performancc of sham, ncocortical and hippocampal lesioned rats in a food search task. Pharmacol Biochem Behav 23:1019-1027.

Hescheler J, Rosenthal W, Trautwein W, Schultz G (1987) The GTP binding protein G0 regulates neuronal calcium channel. Nature 325: $445-447$.

Huang LYM (1992) The excitatory effects of opioids. Neurochem Int 20:463-468.

Igarashi M, Ishii M, Ishikawa K, Himi T (1988) Comparative effect of some neurotrophic agents on balance compensation after labyrinthectomy in the squirrel monkey. In: Postlesion neural plasticity (Flohr $\mathrm{K}$, ed), pp 627-634. Berlin: Springer.

Isaacson RL, Poplawski A (1983) An ACTH $\mathrm{A}_{4-9}$ analng speeds recovery from septal' hyperemotionality in the rat. Behav Neural Biol 39:5259.

Jones KW, Schacffer LC, DeNoble VJ (1989) Systematically administered $N$-methyl-D-aspartate interferes with acquisition of a passive avoidance response in rats. Pharmacol Biochem Behav 34:181-185.

Kim JJ, DeCola JP, Landeira-Fernandez J, Fanselow MS (1991) Nmethyl-D-aspartate receptor antagonist APV blocks acquisition but not expression of fear conditioning. Behav Neurosci 105:126-133.

Klein R, Livingstone S (1950) The effect of adrencorticotropic hormones in epilepsy. J Pediatr 37:733-742.

Koek W, Woods JH, Ornstein P (1987) A simple and rapid method for assessing similarities among directly observable behavioral effects of drugs: PCP-like effects of 2-amino-5-phosphonovalerate in rats. Psychopharmacology 91:297-304.

Landfield PW (1987) Modulation of brain aging correlates by longterm alterations of adrenal steroids and neurally-active peptides. Prog Brain Res 72:279-300.

Leung L, Desborough KA (1988) AP5 a $N$-methyl-D-aspartate receptor antagonist blocks the hippocampal theta rhythm in behaving rats. Brain Res 463:148-152.

Maho C, Villemin, E, Ammassari-teule M (1991) Limited and extensive cueing inversely control spatial learning performance in fornix damaged and nonlesioned rats. Psychobiology 19:323-331.

McDaniel WF, Davall EJ, Walker PE (1989) ACTH(4-9) analog can retard spatial alternation learning in brain damaged and normal rats. Behav Neural Biol 52:271-278.

McNamara RK, Skelton RW (1993) The neuropharmacological and neurochemical basis of place learning in the Morris water maze. Brain Res Rev 18:33-49.

McNaughton BL, Barnes CA, Rao G, Baldin J, Rasmusse M (1986) Long-term enhancement of hippocampal synaptic transmission and the acquisition of spatial information. J Neurosci 6:563-571.

Morris RGM (1989) Synaptic plasticity and learning: selective impairment of learning in rats and blockade of long-term potentiation in vivo by the $N$-methyl-D-aspartate receptor antagonist AP5. J Neurosci 9:3040-3057.

Morris RGM, Anderson E, Lynch GS, Baudry M (1986) Selective impairment of learning and blockade long-term potentiation by $\mathrm{N}$-methyl-D-aspartate receptor agonist AP5. Nature 319:774-776.
Nyakas C, Veldhuis H, De Wied D (1985) Beneficial effect of chronic treatment with ORG2766 and alpha-MSH on impaired reversal learning of rats with bilateral lesions of the parafascicular area. Brain Res Bull 15:257-265.

Oitzl MS, Josephy M, Spruijt BM (1993) Org2766 counteracts the behavioral effects of a mineralocorticoid antagonist. Pharmacol Biochem Behav 44:447-450.

Pentella K, Bachman DS, Sandman CA (1982) Trial of an ACTH(49) analog in children with intractable seizures. Neuropediatrics 13 : $59-62$.

Pitsikas N, Spruijt BM, Algeri S, Gispen WH (1990) The ACTH/ MSH(4-9) analog Org2766 improves retrieval of information after a fimbria fornix transection. Peptides 11:911-914.

Pitsikas N, Spruijt BM, Algeri S, Gispen WH (1991) Effects of Org2766 on recovery after bilateral fimbria fornix lesions. Pharmacol Biochem Behav 38:931-934.

Reul JMHM, Tonnaer JADM, De Kloet ER (1988) Neurotrophic $\Lambda C T H$ analogue promotes plasticity of corticosteroid receptor subtype in brain of senescent male rats. Neurobiol Aging 9:1-7.

Rusin KI, Randic M (1991) Modulation of NMDA-induced currents by $\mu$-opioid receptor agonist DAGO in acutely isolated rat spinal dorsal horn neurons. Neurosci Lett 124:208-212.

Schroeder JE, Fischbach PS, Zheng D, Mc Cleskey EW (1991) Activation of mu-opioid receptors inhibits transient high-and low-threshold $\mathrm{Ca}^{2+}$ currents, but spares a sustained current. Neuron 6:13-20.

Spruijt BM (1992) Org2766 enhances social attention in aging rats: a longitudinal study. Neurobiol Aging 13:153-158.

Spruijt BM, Ellenbroek B, Cools AR, Gispen WH (1986) The colliculus superior modulates ACTH-induced excessive grooming. Life Sci $39: 461-470$.

Spruijt BM, Pitsikas N, Algeri S, Gispen WH (1990) Org2766 improves performance of rats with unilateral lesions in the fimbria fornix in a spatial orientation task. Brain Res 527:192-197.

Spruijt BM, Hol T, Rousseau J (1992) Approach and avoidance behavior of individually recognized animals automatically quantified with an imaging technique. Physiol Behav 51:747-752

Strand FL, Rose KJ, King JA, Segarra AC, Zuccarell LA (1989) ACTH modulation of nerve development and regeneration. Prog Neurobiol $33: 45-85$.

Tartara A, Maurelli PBM, Avoldi F (1983) Centrally administered $\mathrm{N}$-terminal fragments of ACTH (1-10 4-10 4-9) display convulsant properties in rabbits. Peptides 4:315-318.

Terenius I, Gispen WH, De Wied D (1975) ACTH-like peptides and opiate receptors in the rat brain: structure-activity studies. Eur J Pharmacol 33:395-399.

Torda C, Wolff HG (1952) Effects of various concentrations of adrencorticotropic hormone on electrical activity of brain and sensitivity to convulsion inducing agents. Am J Physiol 168:406.

Tortella FC (1988) Endogenous opioids: quieting the seizing brain? Trends Pharmacol Sci 9:366-372.

Trifiletti RR, Pranzatelli MR (1992) Influence of ACTH and ACTH fragments on $(\mathrm{H})$ mk-801 binding to rat hippocampal NMDA receptors. Eur J Pharmacol 226:377-379.

Walker DL, Gold PE (1991) Effects of the novel NMDA antagonist NPC 12626 on long-term potentiation learning and memory. Brain Res 549:213-221.

Wamil A, Croiset C, Kleinrok 7, De Wied D (1991) Beneficial effects of ACTH(4-10) on pilocarpin induced seizures. Neurosci Res Commun 4:109-116.

Willig RP, Lagenstein I (1982) Use of ACTH fragments in children with infantile spasms. Neuropediatrics 13:55-58.

Wolterink G, Van Zanten E, Kamsteeg H, Radhakishun FS, Van Ree JM (1990) Functional recovery after destruction of dopamine systems in the nucleus accumbens of rats. II. Facilitation by the ACTH(49) analog ORG2766. Brain Res 507:101-108. 